\title{
Once-lame duck now exudes self-confidence
}

\section{Parls}

ThE European Space Agency (ESA) is "the best example of what European collaboration can achieve", says its directorgeneral, Reimar Lüst. "We are not only involved with basic science and new technology, but are faced with heavy competition, unlike the European fundamental research facilities, which have life easy."

Yet, with only one-tenth of the budget available to the US National Aeronautics and Space Administration (NASA), ESA has become a force to be reckoned with.

The collaboration began in the early 1960 s, under the impetus of European scientists, as the European Space $\mathrm{Re}$ search Organisation (ESRO) and the European Launcher Development Organisation (ELDO). ESRO was highly successful, developing a series of scientific satellites launched by NASA, and establishing specialized spacescience centres in the Netherlands, Italy and West Germany. But ELDO was a damp squib and failed to produce a viable launcher.

ESRO and ELDO metamorphosed into ESA in 1975 with the signing of a convention by 11 European countries: Belgium, Denmark, West Germany, France, Ireland, Italy, the Netherlands, Spain, Sweden, Switzerland and the United Kingdom. Austria and Norway joined last year, when Finland became an associate member.

ESA has taken European space capability out of a purely scientific domain,

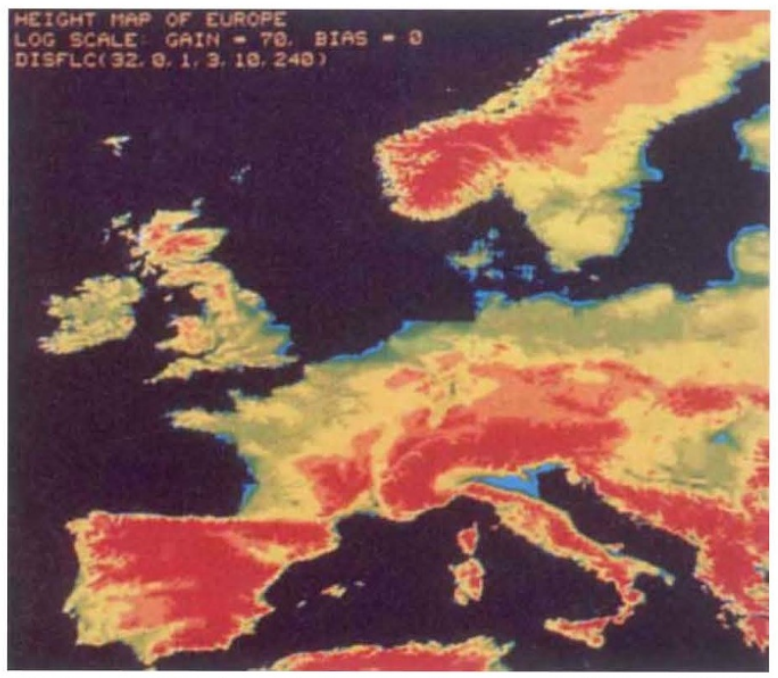
ESA's satellite-view of Europe. Europe could comfortably double spending on space, says ESA's director-general. dependent on US launchers, into telecommunications, Earth observation and meteorology. A major step was the establishment, in 1980, of Arianespace, a commercial joint-stock company (59 per cent owned by France) responsible for the exploitation of ESA's successive generations of Ariane rockets. With a record of only four failures out of 30 launches, Arianespace now has 50 per cent of the world commercial launch market.

Once the heart of European collaboration in space, basic science now represents only 12.4 per cent of ESA's total 1,573 million ECU budget. But the science programme, like the general budget, is mandatory. All member states have to contribute in proportion to their gross national product. Consequently, unanimity is required whenever policy or budget decisions are put to the vote at ministerial-level meetings. Last year,
Britain found itself isolated when it initially refused to agree a 5 per cent annual increase in the science programme budget, holding up scheduling and potentially threatening some projects.

The science programme is constructed around a long-term plan, put together by the science programme committee and covering the next 15 to 20 years. The current programme, called Horizon 2000, was jubilantly approved at the 1985 ESA council meeting at ministerial level, in Rome. It comprises four 'cornerstone' projects in solar terrestrial physics, a comet nucleus sample return mission, an X-ray multi-mirror mission and a submillimetre astronomy project.

For Lüst, the science projects often help the push towards new technology - as was the case with the optics of the Hipparcos astronomy sattelite, one of

four 'medium-sized' missions planned under Horizon 2000. (Hipparcos is due to be launched in a few weeks.) Two others, Ulysses and the Space Telescope, are joint ventures with NASA, and have had to stay on ice for almost three years since the suspension of shuttle launches in 1986. Future ESA missions will be launched by its own Ariane rockets.

The applications programmes are where national passions, purses and fantasies find direct expression. Participation is optionai, but ESA ensures that backing nations receive industrial contracts in proportion to their investment.

Telecommunications satellites have been supported by all member states and, with Earth observation and microgravity projects, have stimulated the European Commission to become involved to work out norms, organize networks of users and to improve what it considers to be an in- adequate infrastructure.

But ESA's most controversial and expensive move, where tangible returns are less certain, came in November 1987 when a majority of member states backed a programme for manned space missions. Together, ESA's contribution of an attached laboratory to the NASA Freedom space station, a free-flying laboratory and a polar platform, now account for almost 40 per cent ( 609 million ECU) of its total budget, while the French-conceived Hermes space plane and the Ariane 5 rocket needed to launch it swallow a further 10 per cent (153 million ECU). Britain has opted out of these projects, so British companies will benefit hardly at all from the contracts.

Lüst applauds the decision to enter the manned space arena. "The trend will move towards robotics, but this will take 20-30 years. Meanwhile, there is still a need for people." $\mathrm{He}$ argues that the Hubble Space Telescope, due to be launched at the end of the year, has been designed to last for ten years. But if it needs repair during that time, "it may be more expensive to recover than to repair it in orbit."

To Lüst, there is no doubt about the value of ESA for European science and industry. "The system really works. On satellite projects, probably two dozen truly European teams work together. Europe needs a drive on high technology and ESA provides an excellent vehicle for this." He is proud that ESA scientists and engineers are already exploring new frontiers such as robotics, synthetic radar and laser applications for optical communication between satellites.

"We also need more civil and less military research", says Lüst. Since 1980, the ESA convention has declared the purpose of its activities as exclusively peaceful, a constraint that has strung out negotiations with NASA over the Freedom space station. He also feels that space science is good value for money. "Europe's gross national product is about three-quarters of that of the United States, yet we spend only one-eighth per capita of what the United States spends on civil research. Only 0.05 per cent goes on space technology. Even if the figure doubled it would still be all right."

But last year, ESA found its member states less united and resolute than in 1985 and is due for a new round of debate when it seeks backing for the Data Relay Satellite, which, according to Lüst, is an essential element of the Columbus package.

Meanwhile, Columbus is not yet out of the woods. President Bush has still to persuade Congress to go ahead with Freedom. But, says, Lüst, if the United States reneges, ESA will continue alone, although it may be more reluctant to cooperate with NASA in the future.

Peter Coles 